\title{
Effects of bio-loggers on behaviour and corticosterone metabolites of Northern Bald Ibises (Geronticus eremita) in the field and in captivity
}

Verena Puehringer-Sturmayr ${ }^{1,2^{*}} \mathbb{0}$, Matthias-Claudio A. Loretto ${ }^{1,3}$, Josef Hemetsberger ${ }^{1,2}$, Tanja Czerny ${ }^{1}$, Johannes Gschwandegger ${ }^{1,3}$, Madelaine Leitsberger ${ }^{1,4}$, Kurt Kotrschal ${ }^{1,2}$ and Didone Frigerio ${ }^{1,2}$

\begin{abstract}
Background: During the past decades, avian studies have profited from the development of miniature electronic devices that allow long-term and long-range monitoring. To ensure data quality and to inform understanding of possible impacts, it is necessary to test the effects of tagging. We investigated the influence of GPS-transmitters on the behaviour and physiology (levels of excreted corticosterone metabolites, CM) of an endangered bird species, the Northern Bald Ibis (Geronticus eremita). We considered effects of GPS-tags in two contexts: (1) aviary (i.e. in captivity), focussing on short-term effects of transmitters on locomotion, foraging and maintenance behaviour (20 individuals that differed in sex and age observed for 10 days) and (2) field, focussing on intermediate-term effects of transmitters on locomotion, foraging, maintenance behaviour, dorsal feather preening, social interactions and physiology (CM) (24 individuals observed for 79 days). In both contexts, focal animals were equipped with bio-logger backpacks mounted with a harness.
\end{abstract}

Results: In the aviary, behavioural observations were limited to the first days after tagging: no differences were found between individuals with GPS-tags and their controls with respect to the behavioural parameters considered. In the field, no behavioural differences were found between the GPS-tagged individuals and their controls; however, 1 month after tagging, individuals with GPS-tags excreted significantly more CM than their controls before returning to baseline levels.

Conclusions: Our results suggest that GPS-transmitters did not affect foraging, locomotion and maintenance behaviour in the Northern Bald Ibis in the short- or intermediate-term. However, they did affect the hypothalamicpituitary-adrenal reactivity in the intermediate-term for 1 month before returning to baseline levels the next month. As the Northern Bald Ibis is listed as endangered, evaluating possible adverse effects of bio-logging is also relevant for potential conservation and reintroduction research.

Keywords: Short-term effects, Bio-tagging, Social behaviour, Birds, Excreted corticosterone metabolites, Body weight, Maintenance behaviour, Intermediate-term effects

\footnotetext{
*Correspondence: verena.puehringer-sturmayr@univie.ac.at

${ }^{1}$ Core Facility Konrad Lorenz Research Centre for Behaviour

and Cognition, University of Vienna, Fischerau 11, 4645 Grünau im Almtal, Austria

Full list of author information is available at the end of the article
}

\section{Background}

During the past decades, device miniaturisation and advancements in battery life have greatly aided researchers in overcoming challenges and constraints for following free-roaming animals $[1,2]$. Avian

c) The Author(s) 2020. This article is licensed under a Creative Commons Attribution 4.0 International License, which permits use, sharing, adaptation, distribution and reproduction in any medium or format, as long as you give appropriate credit to the original author(s) and the source, provide a link to the Creative Commons licence, and indicate if changes were made. The images or other third party material in this article are included in the article's Creative Commons licence, unless indicated otherwise in a credit line to the material. If material is not included in the article's Creative Commons licence and your intended use is not permitted by statutory regulation or exceeds the permitted use, you will need to obtain permission directly from the copyright holder. To view a copy of this licence, visit http://creativeco mmons.org/licenses/by/4.0/. The Creative Commons Public Domain Dedication waiver (http://creativecommons.org/publicdomain/ zero/1.0/) applies to the data made available in this article, unless otherwise stated in a credit line to the data. 
studies, in particular, have benefited from such advances as researchers can now track migratory routes and gain understanding about wintering areas and connectivity in birds [3-6]. The predictive models generated by geographical datasets are of considerable importance not only for conservation biologists, but also for other disciplines, for example, veterinary medicine [2]. Despite these benefits, recent research has emphasised the need to identify any possible effects of GPS-tagging before making inferences about the biology of an animal [7-9]. Meta-analyses of the impacts of GPS-tags suggest that attaching transmitters and similar devices adversely affects behaviour in a range of bird species [1]. The most substantial effects include increased maintenance behaviour (e.g. preening, fluffing and stretching), restlessness, and energy expenditure as well as decreased likelihood of nesting $[1,10,11]$. How potential adverse effects scale with transmitter weight is still not well known ([1] and references therein). It has been suggested that the effects of transmitters weighing less than $5 \%$ of the body weight of an animal would only have negligible effects [12]. However, other studies have suggested that it is advisable not to exceed 3\% [13] — but see Tomotani et al. [14] who conclude that using relative logger weight can be a dangerous assumption in general. McMahon et al. [15] assessed four main categories for describing the potential effects of GPS-tags: (1) those originating from capturing an animal, (2) the type of device, including shape, size and colouration, (3) the method applied for mounting the device, and (4) timing and duration of bio-logging.

The evaluation of the impacts of GPS-tags has animal welfare implications, as some animals may experience a stress response to the device [16]. Physiological parameters such as circulating and/or excreted glucocorticoid levels are usually considered a good indicator of the stress response [17-19]. Glucocorticoid levels increase in response to stressful situations. This is an endocrine mechanism that aids adaptive defensive response [16], but severe chronic stress may have detrimental effects (e.g. reduced reproductive success or impaired memory; $[20,21])$. Thus, additionally to behaviour, physiological measurements might be important in assessing the impact of GPS-loggers on target species. Consideration of such parameters can inform whether the deployment of GPS transmitters is a source of stress for the animal [17-19]. Because invasive physiological surveys may themselves be stressful [22-27], measuring excreted immune-reactive corticosterone metabolites $(\mathrm{CM})$ provides a non-invasive alternative [28-30]. As steroids are metabolised in the liver and excreted into the gut, glucocorticoid metabolite concentrations can be detected in the faeces of mammals or the droppings of birds. Such concentrations have been shown to be representative for the circulating levels [31-34]. Suedkamp Wells et al. [28] showed that captive Dickcissels (Spiza americana) equipped with bio-loggers in the post-breeding season exhibited elevated CM concentrations in the first $24 \mathrm{~h}$ after tagging. Yet excreted glucocorticoid levels returned to baseline levels within $48 \mathrm{~h}$ after tagging, which was interpreted as indicating no long-term effects of the attached loggers. GPS-equipped black-legged kittiwakes (Rissa tridactyla) also showed increased plasma corticosterone levels compared to controls during the early chick rearing phase [35]. These findings underscore the need to investigate potential effects of GPS-devices on the physiology and behaviour of study animals.

The aim of this study is to examine the influence of biologging on the behaviour and physiological parameters of the Northern Bald Ibis (Geronticus eremita). After being listed as critically endangered for many years, this species is now listed as endangered since 2018. Understanding the effects of GPS-transmitters in this system is potentially important for conservation and reintroduction projects (e.g. in Europe and North Africa) that apply telemetry devices for monitoring and research.

We considered the effect of GPS-loggers in two different contexts: (1) a study on Northern Bald Ibis in captivity focussing on short-term effects of GPS-loggers on behaviour (i.e. maintenance behaviour, locomotion, foraging) and (2) a study on free-ranging Northern Bald Ibis focussing on short- and intermediate-term effects of GPS-loggers on behaviour (i.e. maintenance behaviour, dorsal feather preening, locomotion, foraging) and physiological parameters (i.e. excreted immune-reactive corticosterone metabolites). In both contexts, we expected the strongest effects of the GPS-loggers on behaviour shortly after the tagging procedure, as reported from other studies [36-38]. We predicted an increase in maintenance behaviour in GPS-tagged individuals compared with handled birds (experienced handling but not the tagging procedure) or control birds (experienced neither handling nor tagging) since the presence of the device can change the position of the feathers and therefore lead to more self-directed behaviour [39]. We also expected effects of the GPS-transmitters on locomotion and foraging during the first days after attachment because of the increased energy demand caused by the additional weight of the device [39]. In the field, we further tested the effect of the GPS-transmitter on social behaviour (i.e. affiliative and agonistic). In case of a logger effect, we expected GPS-tagged birds to be less engaged in social interactions or even be more frequently a target of agonistic interactions. In addition, excreted immunereactive corticosterone metabolites were assumed to be elevated in the GPS-tagged and handled birds shortly after attachment of the loggers compared to the control 
birds. For intermediate-term effects (11 weeks), we predicted that behavioural and physiological values would return to baseline $[28,40]$. Furthermore, we investigated whether the GPS-tag has an effect on the body weight of the focal individuals. We expected GPS-tagged birds to show a reduction in body weight as compared to the handled and control groups, due to the increased energy demand of the additional weight and drag of the transmitter [39].

\section{Materials and methods}

The aviary context is hereafter presented as "context 1" and the field context as "context 2 ".

\section{Field site and study animals}

In coordination with the European Breeding Programme (EEP, [41]), a free-ranging Northern Bald Ibis colony was established in 1997 at the Konrad Lorenz Research Centre (KLF, Grünau im Almtal, Austria; $47^{\circ} 48^{\prime} \mathrm{E}, 13^{\circ} 56^{\prime} \mathrm{N}$ ) by hand-raising zoo-bred chicks [42, 43]. This was the first free-flying Northern Bald Ibis colony northward the Alps after the species became extinct in the seventeenth century. The aim was to implement basic research to gain know-how for reintroduction and conservation purposes [e.g. 20-22, 44, 45]. The year-round free-flying birds are housed in a large aviary approximately $20 \times 15 \times 7 \mathrm{~m}$ $(L \times B \times H)$ at the Cumberland Wildpark where they are able to flutter around and perform short flights. The birds roam the feeding grounds in the Almtal-region, in a radius of $15 \mathrm{~km}$ of the aviary, returning for roosting at night and for breeding. Supplementary food (hash made from 1-day-old chicks and beef heart, mixed with insects and soaked dog food) is provided twice a day (0800 and 1500 CET) during winter and early spring when natural resources are limited. The birds are well habituated to the close presence of humans, and each of them is marked with an individual combination of coloured leg rings.

\section{Context 1-aviary}

In summer 2013, the aviary was locked for this study for 10 days. At the time of data collection, the colony consisted of 70 individuals, including adult and juvenile birds. Focal animals were 20 birds, chosen randomly with respect to sex (11 females, 9 males) and age (10 adults, i.e. from the 4 th year of age; 10 juveniles, i.e. the 1st year after hatching; according to the age classification proposed by Böhm and Pegoraro [46]). Age ranged from 0.5 to 11 years (mean age $\pm \mathrm{SD}=3.9 \pm 3.8$ ). Ten individuals were fitted with GPS transmitters (logger group: $N_{\text {females }}=5, N_{\text {males }}=5$; mean age $\pm \mathrm{SD}=3.5 \pm 3.9$ ) while 10 served as control (handling group: $N_{\text {females }}=6$, $N_{\text {males }}=4$; mean age $\pm \mathrm{SD}=3.9 \pm 3.9$ ). The list of the focal individuals and their measurements are provided in Table 1.

\section{Context 2-field}

At the time of data collection, in fall 2017, the colony consisted of 45 individuals, including adult and juvenile birds. Focal animals were 24 adult birds (10 females, 14 males). Their age ranged from 2 to 18 years (mean age $\pm \mathrm{SD}=7.1 \pm 4.5$ ). The focal individuals were assigned to two experimental groups and a control group (8 individuals per group): (i) Logger group $\left(N_{\mathrm{fe}}\right.$ males $=4, N_{\text {males }}=4$; mean age $\left.\pm \mathrm{SD}=7.8 \pm 5.1\right)$, birds were equipped with GPS transmitters and experienced handling procedure; (ii) Handling group $\left(N_{\text {females }}=3\right.$, $N_{\text {males }}=5$; mean age $\left.\pm \mathrm{SD}=6.6 \pm 4.6\right)$, birds only experienced handling procedure; (iii) Control group $\left(N_{\mathrm{fe}}\right.$ males $=3, N_{\text {males }}=5$; mean age $\pm \mathrm{SD}=6.9 \pm 4.5$ ), birds were neither equipped with GPS transmitters nor experienced handling procedure. The group assignment was done randomly with respect to sex and age. During the period of data collection, the colony was supplemented with food twice in the morning (0745 and 0945 CET; the total amount of food fed in the morning was identical to the one in the afternoon but split into two feeding situations) and once in the afternoon (1500 CET) to facilitate behavioural observations, which started straight after the first morning feeding, and to prevent the individuals from flying away. The list of the focal individuals and their measurements are provided in Table 2.

\section{Data collection}

Context 1-aviary

Data collection was performed from 2 to 12 July 2013 (10 days) and was divided into three phases (Table 3): phase 1, a 4-day-long phase to collect baseline observations from the behaviour of the birds in the aviary; phase 2, a 2-day-long treatment phase (i.e. capturing and equipping); phase 3 , a further 4-day-long posttreatment observation phase.

Birds were caught on two consecutive days (phase 2) between 0930 and 1430 CET. Captures were done by hand or by using a hand net and avoiding chasing. Several morphological measurements (including body weight for the present study) were taken for different research purposes from all focal individuals. Weighing of individuals ensured that the transmitter did not exceed $3 \%$ of the body weight of the bird ([13]; Table 1), ranging between 1.6 and $2.4 \%$ of the body weight of the single individuals. Ten birds were fitted with a GPS-transmitter. The entire procedure (from catching to releasing) lasted between 15 and 25 min per 
Table 1 Context 1-aviary

\begin{tabular}{|c|c|c|c|c|c|c|c|c|}
\hline Name & Sex & Year of hatching & Age class & Body weight & $\begin{array}{l}\text { Experimental } \\
\text { group }\end{array}$ & Transmitter & $\begin{array}{l}\text { Transmitter } \\
\text { percentage of body } \\
\text { weight }\end{array}$ & $\begin{array}{l}\text { Total duration } \\
\text { of video recordings } \\
\text { (min) }\end{array}$ \\
\hline Kleopatra & $\mathrm{F}$ & 2013 & Juvenile & 1170 & Logger & 1 & 2.39 & 140 \\
\hline Ferdinand & M & 2013 & Juvenile & 1270 & Logger & 1 & 2.20 & 150 \\
\hline Sokrates & M & 2013 & Juvenile & 1200 & Logger & 1 & 2.33 & 150 \\
\hline Esmeralda & $\mathrm{F}$ & 2013 & Juvenile & 1210 & Logger & 1 & 2.31 & 151 \\
\hline Steppenwolf & M & 2002 & Adult & 1190 & Logger & 2 & 1.85 & 155 \\
\hline Winnetouch & $\mathrm{F}$ & 2004 & Adult & 1140 & Logger & 2 & 1.93 & 150 \\
\hline Aleppo & $\mathrm{F}$ & 2006 & Adult & 1240 & Logger & 2 & 1.77 & 150 \\
\hline Cian & M & 2008 & Adult & 1300 & Logger & 2 & 1.69 & 160 \\
\hline Elvis & M & 2013 & Juvenile & 1340 & Logger & 2 & 1.64 & 150 \\
\hline Sequoia & $\mathrm{F}$ & 2009 & Adult & 1100 & Logger & 2 & 2.00 & 150 \\
\hline Kahn & M & 2013 & Juvenile & 1320 & Handling & 0 & 0 & 155 \\
\hline Sophokles & M & 2013 & Juvenile & 1140 & Handling & 0 & 0 & 150 \\
\hline Bazinga & $\mathrm{F}$ & 2013 & Juvenile & 1160 & Handling & 0 & 0 & 155 \\
\hline Baghira & $\mathrm{F}$ & 2013 & Juvenile & 1070 & Handling & 0 & 0 & 150 \\
\hline Hombre & M & 2002 & Adult & 1190 & Handling & 0 & 0 & 154 \\
\hline Goran & $\mathrm{F}$ & 2005 & Adult & 1150 & Handling & 0 & 0 & 160 \\
\hline Loki & $\mathrm{F}$ & 2006 & Adult & 1200 & Handling & 0 & 0 & 154 \\
\hline Shannara & M & 2007 & Adult & 1220 & Handling & 0 & 0 & 160 \\
\hline Schreckse & $\mathrm{F}$ & 2008 & Adult & 1170 & Handling & 0 & 0 & 158 \\
\hline Babsi & $\mathrm{F}$ & 2013 & Juvenile & 1030 & Handling & 0 & 0 & 160 \\
\hline
\end{tabular}

Name, sex, year of hatching, age class, body weight, experimental group, type of transmitter ( 1 =ecotone transmitter 1 , weight $28 \mathrm{~g} ; 2=$ ecotone transmitter 2 , weight $22 \mathrm{~g} ; 0=$ no transmitter), transmitter percentage of body weight and the total duration of video recordings for all focal individuals involved in the study

individual (mean handling durations \pm SD: handling group $=20.7 \pm 3.5$, logger group $=20.6 \pm 2.4$ ).

\section{Context 2-field}

Behavioural data and individual droppings for excreted CM were collected from 25 October 2017 to 11 January 2018 (79 days). Data collection was divided into five phases (Table 3): phase 1, an 11-day-long pre-treatment phase to collect baseline behavioural observations and physiological measurements; phase 2, a 1-day-long treatment phase (handling procedure and transmitter attachment); phase 3, a 10-day-long post-treatment data collection phase; phase 4, a 5-day-long post-treatment phase to perform data collection 1 month later; phase 5 , a 5-day-long post-treatment phase to perform data collection 2 months later. During phase 2, only droppings for $\mathrm{CM}$ analysis were collected; behavioural observations did not take place, as the GPS-transmitters were attached in the morning.

Birds (logger and handling groups) were caught on 1 day (phase 2) between 0815 and 1100 CET. Captures were done by hand or by using a hand net and avoiding chasing. Body weight was taken as a morphological measurement on the day of transmitter attachment (phase 2) and at the end of the experiment (phase 5). Weighing of individuals ensured that the transmitter did not exceed $3 \%$ of the body weight of the birds ([13]; Table 2), ranging between 1.49 and $1.88 \%$ of the body weight of the single individuals [13]. For further statistical analysis, we calculated the weight change ( $\Delta$ body weight) between phase 2 and phase 5. Eight ibises were fitted with a GPS-transmitter. The entire procedure (from catching to releasing) lasted between 13 and 30 min per individual (mean handling durations $\pm S D$ : handling group $=18.6 \pm 4.7$, logger group $=19.6 \pm 4.0$ ).

\section{Transmitter attachment}

Focal animals of the logger group of both contexts (i.e. in captivity and in the field) were fitted with telemetry devices (Ecotone ${ }^{\circledR}$ Telemetry, Sopot, Poland; http://ecoto ne-telemetry.com/en), which were backpack-mounted with a harness following an earlier study by Lindsell et al. ([47], see also Tables 1 and 2). All birds were equipped with either GSM-GPS transmitters, which store the GPS locations and transmit them via GSM network to a server, or UHF-GPS transmitters, from which stored GPS-data can be downloaded via UHF-antenna. All loggers were equipped with solar panels to recharge the batteries. 
Table 2 Context 2 -field

\begin{tabular}{|c|c|c|c|c|c|c|c|}
\hline Name & Sex & Year of hatching & $\begin{array}{l}\text { Start body } \\
\text { weight }\end{array}$ & Experimental group & Transmitter & $\begin{array}{l}\text { Transmitter percentage } \\
\text { of body weight }\end{array}$ & $\begin{array}{l}\text { End } \\
\text { body } \\
\text { weight }\end{array}$ \\
\hline Othello & M & 1999 & 1340 & Logger & 1 & 1.49 & 1360 \\
\hline Aleppo & $\mathrm{F}$ & 2006 & 1180 & Logger & 2 & 1.86 & \\
\hline Cian & M & 2008 & 1330 & Logger & 1 & 1.50 & 1350 \\
\hline North Face & M & 2009 & 1260 & Logger & 2 & 1.75 & 1290 \\
\hline Tiffi & M & 2011 & 1300 & Logger & 1 & 1.54 & 1340 \\
\hline Minerva & $\mathrm{F}$ & 2013 & 1250 & Logger & 2 & 1.76 & 1230 \\
\hline Kira & $\mathrm{F}$ & 2014 & 1185 & Logger & 2 & 1.86 & 1250 \\
\hline Taska & $\mathrm{F}$ & 2014 & 1170 & Logger & 2 & 1.88 & 1200 \\
\hline Hombre & M & 2002 & 1280 & Handling & 0 & 0 & 1370 \\
\hline Simon & M & 2006 & 1360 & Handling & 0 & 0 & 1330 \\
\hline Schreckse & $\mathrm{F}$ & 2008 & 1320 & Handling & 0 & 0 & 1350 \\
\hline Lukas & M & 2012 & 1340 & Handling & 0 & 0 & 1480 \\
\hline Kleopatra & $\mathrm{F}$ & 2013 & 1330 & Handling & 0 & 0 & 1210 \\
\hline Khan & M & 2013 & 1370 & Handling & 0 & 0 & 1430 \\
\hline Chicco & $\mathrm{F}$ & 2014 & 1350 & Handling & 0 & 0 & 1410 \\
\hline Smirne & M & 2015 & 1370 & Handling & 0 & 0 & 1390 \\
\hline Abraxas & M & 2002 & - & Control & 0 & 0 & - \\
\hline Shannara & M & 2007 & - & Control & 0 & 0 & - \\
\hline Hilda & M & 2009 & - & Control & 0 & 0 & - \\
\hline Sequoia & $\mathrm{F}$ & 2009 & - & Control & 0 & 0 & - \\
\hline Ozzy & M & 2010 & - & Control & 0 & 0 & - \\
\hline Mocha & $\mathrm{F}$ & 2014 & - & Control & 0 & 0 & - \\
\hline Simba & M & 2015 & - & Control & 0 & 0 & - \\
\hline Sandro & $\mathrm{F}$ & 2015 & - & Control & 0 & 0 & - \\
\hline
\end{tabular}

Name, sex, year of hatching, start body weight, experimental group, type of transmitter ( 1 = ecotone transmitter 1 , weight $20 \mathrm{~g} ; 2=$ ecotone transmitter 2 , weight $22 \mathrm{~g} ; 0=$ no transmitter), transmitter percentage of body weight and end body weight for all focal individuals involved in the study

Table 3 Phases of the data collection

\begin{tabular}{llc}
\hline Phases & Context 1-aviary & Context 2-field \\
\hline Phase 1 & A 4-day-long pre-treatment observation phase; July & $\begin{array}{c}\text { An 11-day-long pre-treatment data collection phase; October till Novem- } \\
\text { ber }\end{array}$ \\
$\begin{array}{llll}\text { Phase } 2 & \text { A 2-day-long treatment phase (i.e. capturing and equipping); July } & \text { A 1-day-long treatment phase (handling procedure and transmitter } \\
\text { attachment); November }\end{array}$ \\
$\begin{array}{llll}\text { Phase } 3 & \text { A 4-day-long post-treatment observation phase; July } & \text { A 10-day-long post-treatment data collection phase; November } \\
\text { Phase } 4 & - & \begin{array}{c}\text { A 5-day-long post-treatment data collection phase 1 month later; } \\
\text { December }\end{array} \\
\text { Phase } 5 & - & \text { A 5-day-long post-treatment data collection phase 2 months later; Janu- } \\
& \text { ary }\end{array}$
\end{tabular}

\section{Context 1-aviary}

Four birds were equipped with GSM-GPS transmitters (Ecotone transmitter 1: weight $28 \mathrm{~g}$, approximately $2.3 \%$ of the body weight of the birds ranging between
1170 and 1270 g; Table 1). Six ibises were outfitted with UHF-GPS transmitters (Ecotone transmitter 2: weight $22 \mathrm{~g}$, approximately $1.8 \%$ of the body weight of the birds ranging between 1100 and 1340 g; Table 1). 


\section{Context 2-field}

All focal birds in the logger group were equipped with GSM-GPS transmitters (Ecotone transmitter 1: weight $20 \mathrm{~g}$, approximately $1.5 \%$ of the body weight of the birds ranging between 1300 and $1340 \mathrm{~g}$; Ecotone transmitter 2: weight $22 \mathrm{~g}$, approximately $1.8 \%$ of the body weight of the birds ranging between 1170 and 1260 g; Table 2).

In both contexts, the loggers were not removed from the focal individuals after data collection for approximately further 8 months; however, logistical and organisational issues did not allow to further investigate the effects of the deployment.

\section{Behavioural data}

\section{Context 1-aviary}

During the 8 days of phase 1 and 3, every focal individual was video-recorded (Canon Legria FS306) for 10 min twice per day, in the morning between 0900 and 1300 CET and in the afternoon between 1300 and 1800 CET, considering a break of at least $2 \mathrm{~h}$ between repeated observations of the same individual. In total, 16 protocols were collected per individual, adding up to a sum of $3000 \mathrm{~min}$ of observation. Due to technical problems some videos of phase 3 got partly lost (on average $6.9 \mathrm{~min}$ per individual). This was taken into account in the analysis. Videos were analysed using the software Solomon Coder beta (@2013 András Péter). The following behavioural parameters were coded and analysed: duration of locomotion (including walking and flying), frequency of foraging (including drinking, feeding and poking with the bill in the soil), and frequency of maintenance behaviour (including preening, scratching, shaking, stretching, bathing in the sun or in the water; for an exhaustive description of the ethogram of the Northern Bald Ibis see [48]). Videos were coded by JG and ML after calculation of inter-observer reliability using Kappa statistics (Kappa = 8.3, "almost perfect agreement"; [49]).

\section{Context 2-field}

During phases 1, 3, 4 and 5 behavioural observations of focal individuals were collected with the software Prim8 Mobile (mobile computing to record nature, http://www. prim8software.com/; [50]) by applying focal sampling with a continuous recording method [51, 52]. All observations were taken once per day between 0830 and 1200 CET, with each protocol lasting $5 \mathrm{~min}$ per individual. The simultaneous observation of pair partners was avoided to prevent pseudo-replication in social interactions. In total, 719 protocols were collected (on average: $\bar{x} \pm \mathrm{SE}=30 \pm 2$ focal observations per individual). The following behavioural parameters were coded and analysed: duration of maintenance behaviour (including preening, scratching, shaking, fluffing, stretching, sleeping, resting, bathing in the sun or water), dorsal feather preening (preening the area around the logger), locomotion (walking, short distance flights with the focal individual still in sight) and foraging (drinking, feeding, poking with the bill in the soil), as well as frequency of initiated and received affiliative (i.e. greeting, preening, preening invitation, mutual bill shaking, contact sitting) and agonistic (i.e. displacing, threatening, pecking, fighting) interactions (for an exhaustive description of the ethogram of the Northern Bald Ibis see [48]). Behavioural data were collected by VP-S and TC after calculation of inter-observer reliability using intraclass correlation coefficient (package "irr", [53]; coefficient $=0.953$, "excellent reliability", [54]). A ratio per minute was calculated for the durations and the frequencies.

\section{Collection of droppings and analysis of corticosterone metabolites \\ Context 2-field}

To determine concentrations of excreted CM, individual droppings were collected. Droppings represent an integrated, proportional record of the plasma corticosterone levels depending on the gut passage time [32], which we know to be $2-3 \mathrm{~h}$ [55], similar to the records on white ibises (Eudocimus albus, [56]). Daily sample collection was conducted independently of behavioural observations. To account for possible endogenous diurnal variations, droppings were collected from 1600 to 2000 (CET) each day. The collected sample was transferred into an individual Eppendorf ${ }^{\circledR}$ microtube (Eppendorf ${ }^{\circledR}$, Hamburg, Germany) directly after defecation of the focal bird to avoid cross-contamination with other droppings. The samples were stored on ice during collection and within $3 \mathrm{~h}$ frozen at $-20{ }^{\circ} \mathrm{C}$ for $\mathrm{CM}$ analysis. In total, we collected 591 droppings for CM determination (on average: $\bar{x} \pm \mathrm{SE}=25 \pm 3$ droppings per individual).

The analysis was done via an enzyme immunoassay (EIA; [31, 32, 57]) suitable for Northern Bald Ibises [55] at the laboratory of the Department of Behavioural Biology, University of Vienna (Austria). The intra- and interassay coefficients of variance amounted to $9.57 \%$ and $5.54 \%$, respectively.

The measured value of nanogram CM concentration per gramme dropping was taken into further statistical analysis.

\section{Statistical analyses}

All statistical analyses were carried out using the software R 3.4.0 [58] and the packages "lme4" [59], "glmmADMB" [60] and "MuMIn" [61]. We checked whether the residuals were normally distributed through visual inspection and a Shapiro-Wilk test. We used an information-theoretic approach and calculated all possible 
candidate models, ranked them according to their AICc values (second-order form of Akaike's Information Criterion to account for small sample sizes; [62]) and selected the models with $\Delta \mathrm{AICc} \leq 2$ with respect to the top-ranked model for model averaging in order to create model-averaged coefficients [63].

\section{Context 1-aviary}

We defined (1) locomotion, (2) foraging and (3) maintenance behaviour as dependent variables. Generalised linear mixed models (GLMM) were used to investigate whether phase 2, i.e. the 2 days of catching and fitting the birds with GPS-transmitters, had an effect on the behavioural categories. In each set of candidate models the frequency or proportion of one behavioural category served as dependent variable with the following fixed factors in each full model: phase (pre- or post-catching), relative weight of the GPS-transmitter (i.e. percentage of the body weight of the individual; for the handled birds this was zero), sex and age class (adult, juvenile), time of day (i.e. morning and afternoon). We included the phase (i.e. 1 or 3 ) and the relative weight of the transmitter as interaction. Regarding locomotion, we fitted a beta distribution (link = logit); i.e. locomotion was measured as the proportion of observation time. The dependent variable "foraging" contained 133 zeros, and the remaining 170 values varied widely; therefore, it was converted into a binary variable, i.e. foraging or not foraging (family $=$ binomial, link=logit). A negative binomial distribution $($ link $=\log )$ was fitted on the dependent variable "maintenance behaviour" (frequency). The identity of the individual and the day of observation ( 1 to 8 ) were added as random factors to all models.

\section{Context 2-field}

The following parameters were defined as response variables: (1) behaviour (including maintenance behaviour, dorsal feather preening, locomotion, foraging, social interactions), (2) CM and (3) $\Delta$ body weight. Behavioural categories were treated as separate dependent variables in the candidate models. Fixed factors in each full model were experimental group, phase and the interaction term between those two parameters. Sex was not included as a fixed factor, as no effect was found in context 1 regarding logger attachment. Subject identities were included as random factors in all models to control for between subject variation and unbalanced design. GLMMs with an inverse gaussian distribution (link $=\log$ ) were used to assess the effect of GPS transmitter attachment on behaviour. As the inverse gaussian distribution is only able to run with positive values $(>0)$, we added the number 1 to each behavioural category. To investigate the effect on $\mathrm{CM}$ and $\Delta$ body weight, we used Linear mixedeffects models.

\section{Results \\ Context 1-aviary \\ Locomotion}

Age class was the most important predictor, i.e. juveniles moved more than adults (Additional file 1: Tables S1 and S2). Compared to age class, the relative importance of pre/post-catching (i.e. phase 1 and 3), time of day and sex was very low; thus, these factors had a less important effect on locomotion (Additional file 1: Table S2). The interaction term was not included in the top-ranked models (Additional file 1: Table S1). Most importantly, the relative weight of the GPS-transmitters did not occur in the best models; accordingly, the presence and weight of a transmitter were not found to affect the behaviour.

\section{Foraging}

Age class and time of day were the most important predictors, i.e. juveniles were more likely to forage than adults; foraging was more likely to be observed in the afternoon than in the morning (Additional file 1: Table S2). Compared to age class and time of day, all other parameters (i.e. sex, pre/post-catching and relative transmitter weight) had a much lower relative importance and therefore there is little evidence that these factors influenced foraging (Additional file 1: Table S2). The interaction term was not included in the top-ranked models (Additional file 1: Table S1).

\section{Maintenance behaviour}

Time of day was the most important predictor, i.e. in the afternoon maintenance behaviour was observed more frequently (Additional file 1: Table S2). The factor sex also had relatively high importance with 0.82 , i.e. females showed less maintenance behaviour than males. The other parameters pre/post-catching, relative transmitter weight and age class all had very low relative importance, meaning that there is little evidence in this dataset that these fixed factors influenced the frequency of maintenance behaviour (Additional file 1: Table S2). The interaction term was not included in the top-ranked models (Additional file 1: Table S1).

\section{Context 2-field}

\section{Locomotion, foraging and maintenance behaviour}

Phase (i.e. the different phases of the data collection) was the most influential variable regarding the response variables maintenance behaviour, dorsal feather preening, locomotion, foraging (Additional 


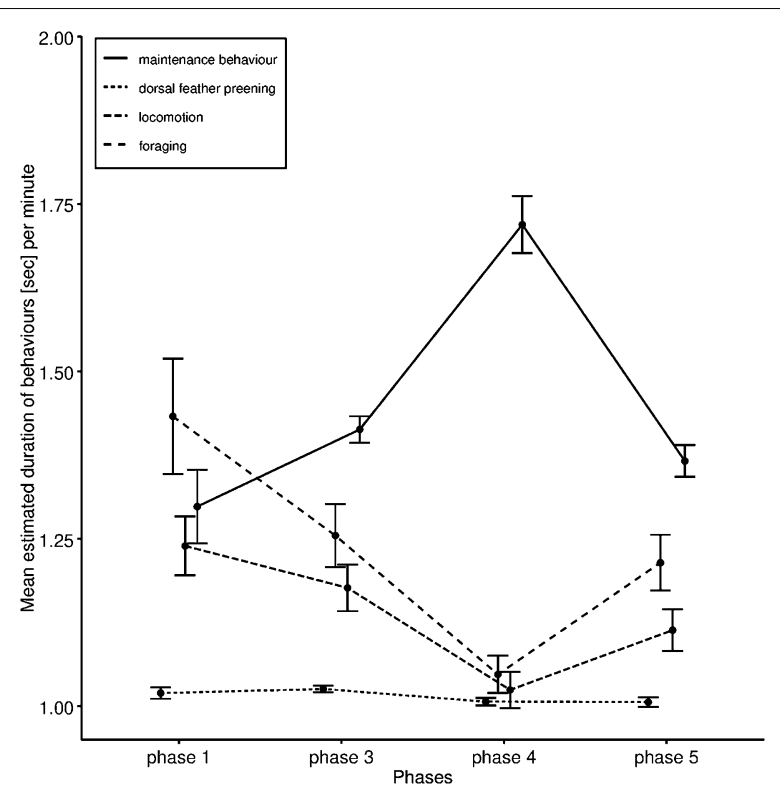

Fig. 1 Context 2-field. Mean estimated durations (s) per minute of locomotion, foraging, maintenance behaviour as well as dorsal feather preening. For a detailed description of the phases, see Table 3. Solid line, maintenance behaviour; dotted line, dorsal feather preening; shortdash, locomotion; longdash, foraging. $N=24$ file 2: Tables S3 and S4). Locomotion and foraging (Fig. 1) declined throughout phases 1 to 4 and showed an increase in phase 5 . The duration of dorsal feather preening only slightly changed during the experiment, whereas a peak in maintenance behaviour was observed in phase 4 (5-day-long post-treatment phase 1 month later) with decreasing durations in phase 5 (5-day-long post-treatment phase 2 months later; Fig. 1). Experimental group and the interaction term were not included in the top-ranked model.

\section{Social behaviour}

Model-averaged results identified phase, experimental group and the interaction term between the two parameters as the strongest determinants of initiated and received affiliative behaviour (Additional file 2: Tables S3 and S4). The affiliative behaviours (initiated and received) increased initially in the GPS-tagged birds compared with the handled and control birds; then we observed a decline in the GPS-tagged birds during phase 4. Furthermore, birds in the control (initiated affiliative behaviour) and handled (initiated and received affiliative behaviour) groups showed a peak during phase 3 and 4 , respectively; in both cases, the frequencies decreased afterwards (Figs. 2 and 3). Received agonistic behaviour was best explained by phase, with decreasing frequencies

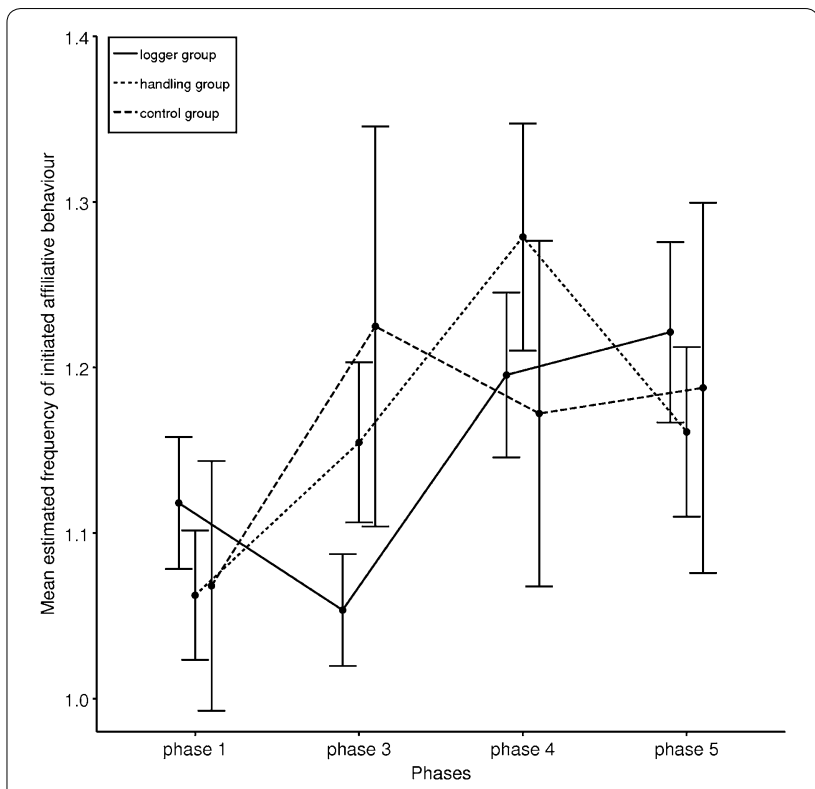

Fig. 2 Context 2-field. Mean estimated frequency of initiated affiliative behaviour in relation to the different phases and experimental groups. For a detailed description of the phases, see Table 3. $N_{\text {LoggerGroup }}=8 ; N_{\text {HandlingGroup }}=8 ; N_{\text {ControlGroup }}=8$

throughout phases 1 to 4 and increasing ones during phase 5 (Additional file 2: Tables S3 and S4). Experimental group and the interaction term were not included in

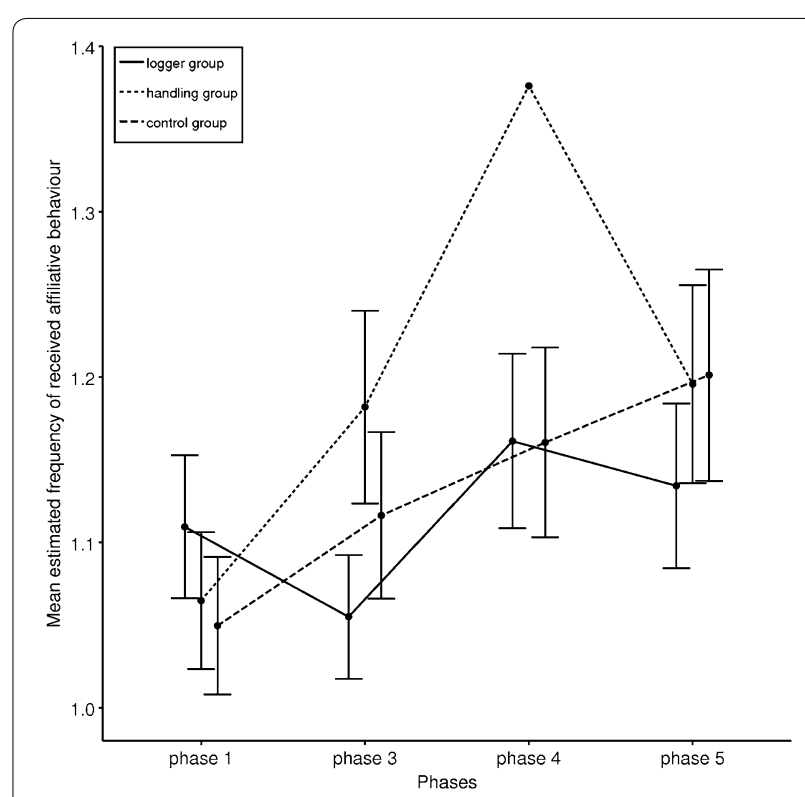

Fig. 3 Context 2-field. Mean estimated frequency of received affiliative behaviour in relation to the different phases and experimental groups. For a detailed description of the phases, see Table 3. $N_{\text {LoggerGroup }}=8 ; N_{\text {HandlingGroup }}=8 ; N_{\text {ControlGroup }}=8$ 
the top-ranked model. Candidate models with initiated agonistic behaviour as response variable did not improve penalised model fit over the null model, as assessed by AICc, indicating that variation in the data cannot be explained by any of the fixed factors.

\section{Corticosterone metabolites}

The excretion pattern of $\mathrm{CM}$ was best explained by phase, experimental group and the interaction term of these fixed factors (Additional file 2: Tables S3 and S4). CM levels of the GPS-tagged birds increased steadily after GPS-transmitter attachment, whereas a decline was observed within the handled birds (Fig. 4). On the contrary, the control birds showed first an increase in CM levels during phase 3 , with decreasing levels afterwards. However, during phase 5, all three experimental groups showed similar CM concentrations.

\section{$\Delta$ Body weight}

The full model did not improve penalised model fit over the null model, as assessed by AICc, indicating that variation in the data cannot be explained by any of these factors.

\section{Discussion}

The deployment of GPS-transmitters on Northern Bald Ibises did not cause remarkable changes in measured behaviour. However, excreted corticosterone metabolites (CM) increased after transmitter attachment during

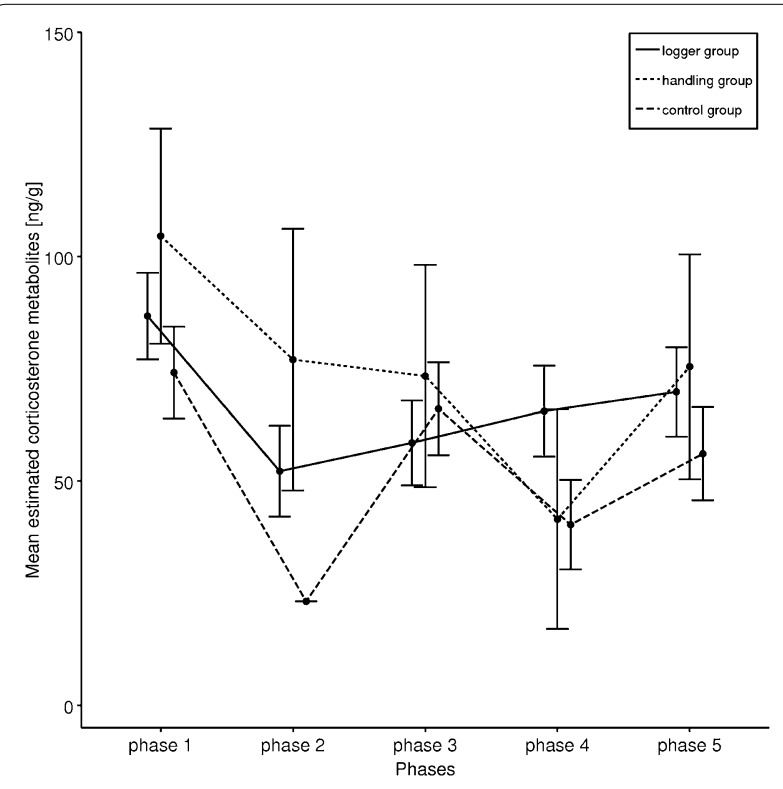

Fig. 4 Context 2-field. Mean estimated CM (ng/g) in relation to the different phases and experimental groups. For a detailed description of the phases, see Table 3. $N_{\text {LoggerGroup }}=8 ; N_{\text {HandlingGroup }}=8$; $N_{\text {ControlGroup }}=8$ month 2 before returning to baseline levels during month 3. Our results indicate that the GPS-transmitters used in the present study (i.e. up to approximately $2.5 \%$ of the body weight of an animal) did not affect foraging, locomotion, maintenance behaviour and dorsal feather preening or received agonistic behaviour in captive and free-flying Northern Bald Ibises during the immediate post-tagging period. The pre- and post-catching phase as well as the relative GPS-transmitter weight in aviary birds (context 1 ) and the variable "experimental group" in the field (context 2) had no or only low relative importance as compared to other factors such as age class, time of day (context 1) or phase (context 2). These outcomes contradict our expectations, as we expected to find the strongest differences between tagged birds and handled and control birds shortly after catching and tagging. In regard to the aviary study (context 1), perhaps behavioural acclimatisation after logger attachment was facilitated compared to free-flying conditions, as not much energy had to be expended for foraging activities. Both weather conditions and GPS transmitters have been shown to affect the energy costs of behaviour [39, 64]. Such constraints can be reflected in elevated cost of foraging [65] or in behavioural response that minimises such costs [66]. Because locomotion, foraging and maintenance behaviour in free-flying Northern Bald Ibis did not seem to be affected by logger deployment in general, we may conclude that the harness-attached GPStransmitters in the present study did not have a negative impact on the behaviour observed. Furthermore, we can likely exclude a possible effect of handling time, as the mean values of procedure duration were similar between the experimental groups.

Despite the overall finding of little measurable effect of the GPS-transmitter on behaviour, affiliative behaviour decreased in the GPS-tagged group after the attachment as compared to the handled and control groups, indicating that the tagged birds experienced some impact after logger deployment. Even though we did not investigate the social network [67] of these birds, one possible explanation for the observed pattern is that GPS-tagged birds moved towards the edge of the network for a short period, and for this reason they initiated and received less affiliative behaviour compared with birds in the handled and control groups. Such behavioural responses could negatively impact reproductive behaviour as breeders are usually better embedded in the social network as compared to non-breeders [68], but this remains to be tested. One of the most substantial effects of GPStagging reported in other studies is the decreased likelihood of nesting [1]. A meta-analysis found the strongest negative effects on reproduction in individuals tagged with neck collars [69]. As we found a clear difference 
between the handled group and the GPS-tagged group, we can conclude that the observed effect was caused by the logger deployment alone and not due to the handling experience. We can further exclude CM levels as a reason for the decline in affiliative behaviour, as the GPS-tagged group excreted similar concentrations as the handled and control birds during phase 3 . Even though the behavioural effect was not long-lasting, a careful consideration of the type and period (i.e. reproductive vs non-reproductive period) of GPS-logger attachment is pertinent.

Our results hint at an effect of GPS-loggers on CM excretion. During phases 1 to 3 , all experimental groups showed similar patterns in CM levels. The low value in the control group during phase 2 could be related to the small sample size, resulting in the differences in $\mathrm{CM}$ concentrations between the groups. As a seasonal effect, CM levels generally decrease in late fall and increase again towards the onset of the mating season [70]; however, this was not the case during phase 4 (December) in the GPS-tagged birds as compared to the handled and control birds. Notably, the CM concentrations in all three experimental groups were comparable at the end of the experiment (January), and therefore this might be considered an intermediate-term effect of GPS-tagging. A seasonal or handling effect on CM level can be excluded as the GPS-tagged birds showed an increase in $\mathrm{CM}$ concentrations, whereas the handled birds showed similar values to the control group. Further, we can exclude an impact of the GPS-logger deployment on CM due to sex or age, as those parameters were taken into account when designing the experimental setup. The impact of the GPS-loggers on CM could be a consequence of our small sample size. However, we accounted for this possibility when defining and choosing the statistical models. Thus, we tend to exclude this possibility, even though confidence in the pattern would benefit from a greater sample size generating more robust results. Glucocorticoid concentrations have been shown to increase with handling time [71]. Therefore, we cannot exclude a possible effect of individual differences in reacting to stressful situations; for instance, small differences in handling time between individuals might have affected the results. Furthermore, we also cannot exclude potential impacts on the flight performance of the GPS-tagged birds as we did not measure flight behaviour. A recent study showed that flight speed reduces depending on how heavy the bird is after tagging [14], which would certainly have an impact on wild birds. Thus, a more thorough consideration of flight performance would be necessary. Still, the detected effect in the GPS-tagged birds could have consequences for their subsequent reproductive success, due to the possible increase in energy expenditure during the winter period. Under natural conditions such increased energetic expenditure during winter could eventuate in less available energy allocated to reproduction, i.e. building a nest, producing eggs and raising chicks. We did not detect changes in body weight in relation to logger deployment in the present study, and therefore one could argue that GPS-tagged individuals in this study had enough energy available for survival and investment into the breeding season.

Compared to the adult birds, juveniles showed more locomotion and foraging behaviour. Both foraging and maintenance behaviours occurred more often in the afternoon than in the morning, which was independent of the presence of a GPS-transmitter. Thus, when testing the effects of GPS-loggers in animals, it is important to account for different age classes and time of day that could mask variation caused by transmitter effects. A detailed discussion of these results is beyond the scope of this study. However, there is evidence from other studies that juvenile and sub-adult birds had lower foraging efficiency compared with adults and experienced individuals, which may force juveniles to migrate later than adults $[47,72]$. In our study, yearling juvenile birds were observed foraging more frequently than adult birds, irrespective of being equipped with a transmitter or not. The hierarchy within the colony is another factor worth considering: sub-adults and especially juveniles after fledging (as in our case) are low in rank and often get displaced by adult birds, who pose a risk to scrounge their food $[48,73]$. Thus, age and time of day can have significant effects that require scrutiny per study species when tagging is considered.

\section{Conclusions}

This study was performed on a globally endangered species, for which the kind of data that can be collected by GPS telemetry could be essential to manage its conservation. For example, GPS technology is used to monitor endangered species, their threats and to protect their habitats [74] or to detect poaching events [75]. At the same time, given the small population size, individual birds of this species are disproportionally important for reproduction. For both reasons, it is highly relevant to identify and minimise potential effects of GPS-loggers on this species. In the present study, we found no long-term effects of GPStransmitters below $3 \%$ of the body weight of an animal on locomotion, foraging, maintenance and agonistic behaviour in the Northern Bald Ibis. However, affiliative behaviour and the excretion pattern of $\mathrm{CM}$ were temporarily affected by tagging. Our results imply that a closer look at physiological parameters is important 
to detect whether there is an effect on the stress level of the GPS-tagged animals, even though no behavioural changes might be observed after logger deployment. These findings are relevant for conservation and management projects running on species that include the use of animal-carried bio-loggers.

\section{Supplementary information}

Supplementary information accompanies this paper at https://doi. org/10.1186/s40317-019-0191-5.

Additional file 1: Table S1 and Table S2. Context 1 - Aviary. Top-ranked models form the generalized linear mixed models and model-averaged coefficients (full-model averaging).

Additional file 2: Table S3 and Table S4. Context 2 - Field. Top-ranked models from the linear mixed effects models and generalized linear mixed models as well as model-averaged coefficients of final models.

\section{Abbreviations}

AIC: Akaike's Information Criterion; Cl: confidence interval; CM: excreted immune-reactive corticosterone metabolites; EEP: European Breeding Programme; EIA: enzyme immunoassay; GLMM: generalised linear mixed models; GSM: Global System for Mobile Communications; GPS: Global Positioning System; KLF: Core facility "Konrad Lorenz Research Centre" for Behaviour and Cognition, University of Vienna; SD: standard deviation; SE: standard error; UHF: ultra-high frequency.

\section{Acknowledgements}

We gratefully acknowledge Julia Krejci for helping with catching and outfitting the ibises with GPS-transmitters, Georgine Szipl for promoting discussion on the topic, Vanessa Rohatsch and Katja Mück for assistance with data collection and Sonia Kleindorfer for language editing.

\section{Authors' contributions}

DF, JH, M-CAL and VP-S conceived the study. JG, ML collected the data and analysed the videos for context 1, VP-S and TC collected the data for context 2. M-CAL and VP-S performed statistical analyses. DF, VP-S, ML, JG, M-CAL, JH, KK, TC wrote the paper, with DF, VP-S and M-CAL providing major contributions. All authors read and approved the final manuscript.

\section{Funding}

Financial support was provided by the Austrian Federal Ministry for Science, Research and Economy (GZ: BMWFW-66.006/0026-WFN/3b/2014) for the acquisition of the transmitters. The "Verein der Förderer der Konrad Lorenz Forschungsstelle", and the "Herzog von Cumberland Stiftung" provided permanent support. DF and VP-S were funded by the programmes Sparkling Science, Project SPA-05/26 and Top Citizen Science, Project TCS-02/06; TC was funded by the OeAD-GmbH (Programme Sparkling Science, Project SPA05/26); M-CAL was funded by the FWF (Austrian Science Fund) programmes Y366-B17 and W1234. DF was additionally funded by the "Back-to-ResearchGrant" of the University of Vienna, Faculty of Life Sciences and by the FFG programme Bridge, Project number 858551 . Open access funding provided by University of Vienna.

\section{Availability of data and materials}

The datasets used and/or analysed during the current study are available from the corresponding author on reasonable request.

\section{Ethics approval and consent to participate}

Not applicable: the study does not involve humans.All authors adhered to the 'Guidelines for the use of animals in research' as published in Animal Behaviour (1991, 41, 183-186). This study complies with all current Austrian laws and regulations concerning work with wildlife. The experimental setup was performed under Animal Experiment Licence Numbers BMWFW-66.006/0011WF/II/3b/2014 and BMWFW-66.006/0026-WF/V/3b/2014 by the Austrian Federal Ministry for Science and Research. We confirm that the owner of the land, the Duke of Cumberland, gave permission to conduct the study on this site. Birds were habituated to the presence of humans.

\section{Consent for publication}

Not applicable.

\section{Competing interests}

All authors have seen the final manuscript and take responsibility for its content. The authors declare that they have no competing interests.

\section{Author details}

${ }^{1}$ Core Facility Konrad Lorenz Research Centre for Behaviour and Cognition, University of Vienna, Fischerau 11, 4645 Grünau im Almtal, Austria. 2 Department of Behavioural Biology, University of Vienna, Althanstrasse 14, 1090 Vienna, Austria. ${ }^{3}$ Department of Cognitive Biology, University of Vienna, Althanstrasse 14, 1090 Vienna, Austria. ${ }^{4}$ Centre for Animal Welfare, University of Winchester, Sparkford Road, Winchester SO22 4NR, UK.

Received: 31 October 2018 Accepted: 27 December 2019

Published online: 15 January 2020

\section{References}

1. Barron DG, Brawn JD, Weatherhead PJ. Meta-analysis of transmitter effects on avian behaviour and ecology. Methods Ecol Evol. 2010;1:180-7.

2. Kays R, Crofoot MC, Jetz W, Wikelski M. Terrestrial animal tracking as an eye on life and planet. Science. 2015;348:aaa2478.

3. Stuchbury BJM, Tarof SA, Done T, Gow E, Kramer PM, Tautin J, et al. Tracking long-distance songbird migration by using geolocators. Science. 2009;323:896

4. Bairlein F, Norris DR, Nagel R, Bulte M, Voigt CC, Fox JW, et al. Crosshemisphere migration of a 25 g songbird. Biol Lett. 2012;8:505-7.

5. Arlt D, Low M, Pärt T. Effect of geolocators on migration and subsequent breeding performance of a long-distance passerine migrant. PLOS ONE. 2013;8:e82316.

6. Klaassen RHG, Hake M, Strandberg R, Koks BJ, Trierweiler C, Exo K-M, et al. When and where does mortality occur in migratory birds? Direct evidence from long-term satellite tracking of raptors. J Anim Ecol. 2014;83:176-84.

7. Wanless S. Effects of tail-mounted devices on the attendance behavior of kittiwakes during chick rearing. J F Ornithol. 1992;63:169-76.

8. Hiraldo F, Donázar JA, Negro JJ. Effects of tail-mounted radio-tags on adult lesser kestrels. J F Ornithol. 1994;65:466-71.

9. Wilson RP, McMahon CR. Measuring devices on wild animals: what constitutes acceptable practice? Front Ecol Environ. 2006:4:147-54.

10. Mateo-Moriones A, Villafuerte R, Ferreras P. Evaluation of radiotagging techniques and their application to survival analysis of Red-legged Partridge Alectoris rufa chicks. Ibis (Lond 1859). 2012;154:508-19.

11. Godfrey JD, Bryant DM, Williams MJ. Radio-telemetry increases free-living energy costs in the endangered Takahe Porphyrio mantelli. Biol Conserv. 2003;114:35-8.

12. Brander RB, Cochran WW. Radio location telemetry. In: Giles Jr RH, editor. Wildlife management techniques. Washington, DC: The Wildlife Society; 1969.

13. Phillips RA, Xavier JC, Croxall JP. Effects of satellite transmitters on albatrosses and petrels. Auk. 2003;120:1082-90.

14. Tomotani BM, Bil W, van der Jeugd HP, Pieters RPM, Muijres FT. Carrying a logger reduces escape flight speed in a passerine bird, but relative logger mass may be a misleading measure of this flight performance detriment. Methods Ecol Evol. 2019;10:70-9.

15. McMahon CR, Collier N, Northfield JK, Glen F. Taking the time to assess the effects of remote sensing and tracking devices on animals. Anim Welf. 2011;20:515-21.

16. Möstl E, Palme R. Hormones as indicators of stress. Domest Anim Endocrinol. 2002;23:67-74

17. Ropert-Coudert Y, Wilson RP. Trends and perspectives in animal-attached remote sensing. Front Ecol Environ. 2005;3:437-44.

18. Hawkins P. Bio-logging and animal welfare: practical refinements. Mem Natl Inst Polar Res Spec Issue. 2004;58:58-68. 
19. Schulz JH, Millspaugh JJ, Washburn BE, Bermudez AJ, Tomlinson JL, Mong TW, et al. Physiological effects of radiotransmitters on mourning doves. Wildl Soc Bull. 2005;33:1092-100.

20. Cyr NE, Romero LM. Chronic stress in free-living European starlings reduces corticosterone concentrations and reproductive success. Gen Comp Endocrinol. 2007;151:82-9.

21. Bowman RE, Beck KD, Luine VN. Chronic stress effects on memory: sex differences in performance and monoaminergic activity. Horm Behav. 2003:43:48-59.

22. Gessaman JA, Nagy KA. Transmitter loads affect the flight speed and metabolism of homing pigeons. Condor. 1988;90:662-8.

23. Schulz JH, Bermudez AJ, Tomlinson JL, Firman JD, He Z. Effects of implanted radiotransmitters on captive mourning doves. J Wildl Manage. 1998:62:1451-60.

24. Vleck CM, Vertalino N, Vleck D, Bucher TL. Stress, corticosterone, and heterophil to lymphocyte ratios in free-living Adélie penguins. Condor. 2000;102:392-400.

25. Roy C, Woolf A. Effects of hunting and hunting-hour extension on mourning dove foraging and physiology. J Wildl Manage. 2001;65:808-15.

26. Hamilton GD, Weeks HP Jr. Cortisol and aldosterone comparisons of Cottontail rabbits collected by shooting, trapping, and falconry. J Wildl Dis. 1985;21:40-2.

27. Le Maho Y, Karmann H, Briot D, Handrich Y, Robin JP, Mioskowski E, et al. Stress in birds due to routine handling and a technique to avoid it. Am J Physiol Regul Integr Comp Physiol. 1992;32:R775-81.

28. Suedkamp Wells KM, Washburn BE, Millspaugh JJ, Ryan MR, Hubbard MW. Effects of radio-transmitters on fecal glucocorticoid levels in captive dickcissels. Condor. 2003;105:805-10.

29. Wasser SK, Hunt KE, Brown JL, Cooper K, Crockett CM, Bechert U, et al. A generalized fecal glucocorticoid assay for use in a diverse array of nondomestic mammalian and avian species. Gen Comp Endocrinol. 2000;120:260-75

30. Ludders JW, Langenberg JA, Czekala NM, Erb HN. Fecal corticosterone reflects serum corticosterone in Florida sandhill cranes. J Wildl Dis. 2001;37:646-52

31. Möstl E, Rettenbacher S, Palme R. Measurement of corticosterone metabolites in birds' droppings: an analytical approach. Ann NY Acad Sci. 2005:1046:17-34.

32. Palme R, Möstl E. Measurement of cortisol metabolites in faeces of sheep as a parameter of cortisol concentration in blood. Zeitschrift für Säugetierkd Int J Mamm Biol. 1997;62:192-7, Suppl II.

33. Touma C, Palme R. Measuring fecal glucocorticoid metabolites in mammals and birds: the importance of validation. Ann N Y Acad Sci. 2005; 1046:54-74.

34. Palme R. Measuring fecal steroids: guidelines for practical application. Ann N Y Acad Sci. 2005;1046:75-80.

35. Heggøy O, Christensen-Dalsgaard S, Ranke PS, Chastel O, Bech C. GPS-loggers influence behaviour and physiology in the black-legged kittiwake Rissa tridactyla. Mar Ecol Prog Ser. 2015;521:237-48.

36. Chivers LS, Hatch SA, Elliott KH. Accelerometry reveals an impact of shortterm tagging on seabird activity budgets. Condor. 2016:118:159-68.

37. Lameris TK, Kleyheeg E. Reduction in adverse effects of tracking devices on waterfowl requires better measuring and reporting. Anim Biotelemetry. 2017;5:1-14.

38. Lamb JS, Satgé YG, Fiorello CV, Jodice PGR. Behavioral and reproductive effects of bird-borne data logger attachment on Brown Pelicans (Pelecanus occidentalis) on three temporal scales. J Ornithol. 2017;158:617-27.

39. Enstipp MR, Frost J, Hollmén TE, Andrews RD, Frost $C$. Two methods of radio transmitter attachment and their effects on the behavior and energetics of captive long-tailed ducks (Clangula hyemalis) during winter. Anim Biotelemetry. 2015;3:36

40. Quillfeldt P, McGill RAR, Furness RW, Möstl E, Ludynia K, Masello JF. Impact of miniature geolocation loggers on a small petrel, the thin-billed prion Pachyptila belcheri. Mar Biol. 2012;159:1809-16.

41. Böhm C. Ten years of Northern bald ibis EEP: a review. In: Boehm C, editor. 2nd international EEP studbook. Innsbruck: Alpenzoo; 1999. p. 73-88.

42. Tuckova K, Zisser B, Kotrschal K. Versuch der Ansiedlung einer ortsfesten Waldrapp-Kolonie an der Konrad Lorenz Forschungsstelle. ÖKOL. 1998:20:3-14

43. Kotrschal K. Konrad Lorenz Forschungsstelle: Northern Bald Ibis Project 1997-2006: an update. In: North Bald Ibis Conserv Work
Rep-Proceedings of the 2nd meeting Int Advis Gr North Bald Ibis. Vejer, Spain; 2007. p. 64-6.

44. Loretto M-C, Schloegl C, Bugnyar T. Northern bald ibises follow others' gaze into distant space but not behind barriers. Biol Lett. 2010;6:14-7.

45. Szipl G, Boeckle M, Werner SAB, Kotrschal K. Mate recognition and expression of affective state in croop calls of Northern Bald lbis (Geronticus eremita). PLoS ONE. 2014;9:e88265.

46. Böhm C, Pegoraro K. Der Waldrapp. Hohenwarsleben: Westarp Wissenschaften-Verlagsgesellschaft mbH; 2011.

47. Lindsell JA, Serra G, Peske L, Abdullah MS, AI Qaim G, Kanani A, et al. Satellite tracking reveals the migration route and wintering area of the Middle East population of Critically Endangered northern bald ibis Geronticus eremita. Oryx. 2009:43:329-35.

48. Pegoraro K. Zur Ethologie des Waldrapps (Geronticus eremita L.). Beobachtungen in Volieren und im Freiland (Türkei, Marokko). Innsbruck: University of Innsbruck; 1992

49. Viera AJ, Garrett JM. Understanding interobserver agreement: the kappa statistic. Fam Med. 2005:37:360-3.

50. McDonald M, Johnson S. 'There's an app for that': a new program for the collection of behavioural field data. Anim Behav. 2014:95:81-7.

51. Altmann J. Observational study of behavior: sampling methods. Behaviour. 1974:49:227-67.

52. Martin P, Bateson P. Measuring behavior. An introductory guide. 3rd ed. New York: Cambridge University Press; 2007

53. Gamer M, Lemon J, Fellows I, Singh P. irr: various coefficients of interrater reliability and agreement. $R$ package version $0.84 .1 ; 2012$. https://cran.rproject.org/package=irr. Accessed June 2018

54. Koo TK, Li MY. A guideline of selecting and reporting intraclass correlation coefficients for reliability research. J Chiropr Med. 2016;15:155-63. https:// doi.org/10.1016/j.jcm.2016.02.012.

55. Puehringer-Sturmayr $\vee$, Wascher CAF, Loretto M-C, Palme R, Stoewe M, Kotrschal K, et al. Seasonal differences of corticosterone metabolite concentrations and parasite burden in northern bald ibis (Geronticus eremita): the role of affiliative interactions. PLoS ONE. 2018;13:e0191441.

56. Adams EM, Frederick PC, Larkin ILV, Guillette LJ Jr. Sublethal effects of methylmercury on fecal metabolites of testosterone, estradiol, and corticosterone in captive juvenile white ibises (Eudocimus albus). Environ Toxicol Chem. 2009:28:982-9.

57. Palme R, Rettenbacher S, Touma C, El-Bahr SM, Möstl E. Stress hormones in mammals and birds: comparative aspects regarding metabolism, excretion, and noninvasive measurement in fecal samples. Ann N Y Acad Sci. 2005:1040:162-71.

58. R Core Team. R: a language and environment for statistical computing. Vienna: R Foundation for Statistical Computing; 2017. http://www.r-proje ct.org. Accessed June 2018

59. Bates D, Maechler M, Bolker B, Walker S. Fitting linear mixed-effects models using Ime4. J Stat Softw. 2015:67:1-48.

60. Fournier DA, Skaug HJ, Ancheta J, lanelli J, Magnusson A, Maunder M, et al. AD Model Builder: using automatic differentiation for statistical inference of highly parameterized complex nonlinear models. Optim Methods Softw. 2012;27:233-49.

61. Barton K. MuMIn: Multi-Model Inference. R package version 1.15.6; 2016. https://cran.r-project.org/package=MuMln. Accessed June 2018.

62. Hurvich CM, Tsai C-L. Regression and time series model selection in small samples. Biometrika. 1989;76:297-307.

63. Burnham K, Anderson D. Model selection and multi-model inference: a practical information-theoretic approach. New York: Springer; 2002.

64. Elliott KH, Chivers LS, Bessey L, Gaston AJ, Hatch SA, Kato A, et al. Windscapes shape seabird instantaneous energy costs but adult behavior buffers impact on offspring. Mov Ecol. 2014;2:17.

65. Heath JP, Gilchrist HG. When foraging becomes unprofitable: energetic of diving in tidal currents by common eiders wintering in the Arctic. Mar Ecol Prog Ser. 2010;403:279-90.

66. Drent RH, Daan S. The prudent parent: energetic adjustments in avian breeding. Ardea. 1980;68:225-52.

67. Farine DR, Whitehead $\mathrm{H}$. Constructing, conducting and interpreting animal social network analysis. J Anim Ecol. 2015;84:1144-63.

68. Czerny TM. Investigating social structure in Northern bald ibises (Geronticus eremita) by social network analysis. Vienna: University of Vienna; 2018.

69. Bodey TW, Cleasby IR, Bell F, Parr N, Schultz A, Votier SC, et al. A phylogenetically controlled meta-analysis of biologging device effects on birds: 
deleterious effects and a call for more standardized reporting of study data. Methods Ecol Evol. 2017;9:946-55.

70. Hirschenhauser K. Steroidhormone aus Kot und Sozialverhalten bei Graugänsen (Anser anser). Vienna: University of Vienna; 1998.

71. Sockman KW, Schwabl H. Plasma corticosterone in nestling American Kestrels: effects of age, handling stress, yolk androgens, and body condition. Gen Comp Endocrinol. 2001;122:205-12.

72. Lindsell JA, Shehab AH, Anderson GQA. Patchiness in prey levels increases vulnerability of critical endangered northern bald ibises Geronticus eremita on their Syrian breeding grounds. Bird Conserv Int. 2011;21:274-83.

73. Sorato E, Kotrschal K. Hormonal and behavioural symmetries between the sexes in the northern bald ibis. Gen Comp Endocrinol. 2006;146:265-74.
74. Berger-Tal O, Lahoz-Monfort JJ. Conservation technology: the next generation. Conserv Lett. 2018;11:e12458.

75. O'Donoghue P, Rutz C. Real-time anti-poaching tags could help prevent imminent species extinctions. J Appl Ecol. 2016;53:5-10.

\section{Publisher's Note}

Springer Nature remains neutral with regard to jurisdictional claims in published maps and institutional affiliations.
Ready to submit your research? Choose BMC and benefit from:

- fast, convenient online submission

- thorough peer review by experienced researchers in your field

- rapid publication on acceptance

- support for research data, including large and complex data types

- gold Open Access which fosters wider collaboration and increased citations

- maximum visibility for your research: over $100 \mathrm{M}$ website views per year

At BMC, research is always in progress.

Learn more biomedcentral.com/submissions 